\title{
Molecular species identification of whale meat in South Korean markets
}

\author{
S-M. Lee ${ }^{1}$, Y-Y. Choi ${ }^{2}$, M-S. Min ${ }^{1}$, H. Lee ${ }^{1}$ and M-Y. Lee ${ }^{3}$ \\ ${ }^{1}$ The Research Institute for Veterinary Science, College of Veterinary \\ Medicine, Seoul National University, Republic of Korea; and Conservation \\ Genome Resource Bank for Korean Wildlife (CGRB), College of Veterinary \\ Medicine, Seoul National University, Republic of Korea \\ ${ }^{2}$ Oceans Committee, Korean Federation for Environmental Movements, \\ Seoul, South Korea \\ ${ }^{3}$ DNA Analysis Division, Seoul Institute, National Forensic Service, Seoul, \\ Republic of Korea
}

Corresponding author: H. Lee / M-Y Lee

E-mail: hanglee@sun.ac.kr / muyeonglee@gmail.com

Genet. Mol. Res. 18 (2): gmr18171

Received October 04, 2018

Accepted May 13, 2019

Published May 28, 2019

DOI http://dx.doi.org/10.4238/gmr18171

\begin{abstract}
Commercial whaling has been banned since the moratorium of the International Whaling Commission in 1986. However, domestic sale of cetaceans that are caught as bycatch is still allowed in South Korea. Although whale meat is not very popular in South Korea, it is consumed in certain areas. To identify the species composition of whale meat in South Korean markets, we collected 54 samples that were sold as minke whale meat at restaurants and markets of four cities: Seoul, Ulsan, Busan, and Pohang. Of the 54 whale meat samples, 51 were successfully identified using the partial mitochondrial cytochrome $b$ gene (806-1,140 bp) amplified for species identification. Molecular species identification revealed three species among the samples: minke whale $(52 \%)$, common dolphin (22\%), and narrow-ridged finless porpoise (26\%). We also gathered data for cetacean bycatch in South Korea. In total, 19 species were confirmed to be incidentally caught in South Korea over the past 13 years, and minke whale (13\%), common dolphin (30\%), and narrowridged finless porpoise $(45 \%)$ were recorded as the most frequently caught species. The sale of "fake" minke meat in the markets may
\end{abstract}


have been due to a lack of availability of minke meat, as well as the difference in market values of meat from baleen and toothed whales. These factors that lead to the sale of "fake" minke meat are thought to be contributing causes of the illegal, unregulated, and unreported exploitation of small cetaceans. To prevent such exploitation, it is necessary to continuously monitor whale meat using molecular species identification. Our study improves the understanding of which species of whales (meat) are sold in South Korea and proposes a management policy for the conservation of small cetaceans in South Korea.

Key words: Whaling; Narrow-ridged finless porpoise; Bycatch; Whale meat

\section{INTRODUCTION}

Since the whaling moratorium of the International Whaling Commission (IWC) in 1986, the major threats to marine mammal species and populations are anthropogenic factors, such as pollution, habitat destruction, and bycatch (Lewison et al., 2004). Bycatch, one of the greatest threats to smaller-sized marine mammal populations, is the inadvertent capture and killing of non-target species; it occurs when cetaceans are unable to avoid capture or are entangled in fishing gear. To estimate the actual amount of bycatch and thus develop efficient conservation management policies, the IWC receives annual reports on bycatch from its signatories. Although the report is required to be as accurate as possible, events of illegal, unregulated, and unreported (IUU) exploitation have been found to be omitted from annual bycatch reports, thus distorting the true extent of bycatch.

The Republic of Korea (South Korea) is a member of the IWC. Direct fishing of cetaceans is prohibited in South Korea; however, cetaceans that are incidentally captured in fisheries bycatch can be sold in markets. A fisherman who unintentionally catches cetaceans has a duty to report their bycatch to the maritime police of South Korea, who then investigate whether the fisherman poached the cetacean. Only whales that are shown to have died by stranding or in bycatch are legally allowed to be traded in the market and consumed as whale bushmeat in South Korea. However, genetic monitoring has shown that IUU individuals are sold in markets as whale meat in cities of South Korea (Baker et al., 2006).

Of the 65 countries that consume whale meat, South Korea is the fifth largest consumer (Costello and Baker, 2011). In South Korea, whale meat is not very popular, but it is regarded as a local delicacy mainly in the southeastern coastal cities of Ulsan, Busan, Gyeongju, and Pohang (Tatar, 2014). Minke whale meat is the best-selling owing to its preferred flavor. More than 400 minke whale individuals are thought to be consumed annually in South Korea (Han, 2012). However, this number is presumed to be an underestimation because of the high probability of illegally caught and distributed meat in the market. In addition, Baker et al. (2006) reported that small-toothed whales, such as the narrow-ridged finless porpoise, are also consumed as whale meat; thus indicating the existence of IUU individuals. Given this situation, more systematic research is urgently needed to develop more effective management methods and conservation actions. 
It is usually difficult to identify the original species of a processed wildlife product based on its external characteristics. Molecular species identification is a useful tool that can resolve this challenge. In this study, molecular species identification was used to identify the species composition of whale meat in the restaurants and markets of four South Korean cities: Seoul, Ulsan, Busan, and Pohang.

\section{MATERIAL AND METHODS}

\section{Sampling and DNA extraction}

From July 2012 to June 2015, whale meat (skin, blubber, muscle tissue, and internal organs) sold as minke whale was purchased from restaurants and markets in four cities in South Korea: Seoul, Ulsan, Busan, and Pohang. Each sample of whale meat was collected separately from one plate in each restaurant or one lot in each store. In total, 54 whale meat samples were obtained and stored at $-20^{\circ} \mathrm{C}$ until DNA extraction.

\section{DNA extraction, PCR amplification, and sequencing}

Whole genome DNA was extracted from the whale meat samples using a DNeasy Blood \& Tissue Kit (QIAGEN, Germantown, MD, USA), following the manufacturer's protocols. The mitochondrial cytochrome $b$ gene is a useful marker for molecular species identification and has been used in identifying bush meat (Jain et al., 2007; Alexandra et al., 2012). We amplified the mitochondrial cytochrome $b$ gene using the set of primers: L14724 and H15915 for mammal species (Irwin et al., 1991). A $30 \mu \mathrm{L}$ amplification mixture containing 10-20 ng of the template DNA, $50 \mathrm{mM} \mathrm{KCl}, 10 \mathrm{mM}$ Tris- $\mathrm{HCl}, 1.5 \mathrm{mM} \mathrm{MgCl}_{2}$, 10 pmol each primer, and 1 unit Ex Taq polymerase (iNtRON Biotechnology, Seoul, South Korea) was used. The cycling profile consisted of an initial denaturation at $94^{\circ} \mathrm{C}$ for $4 \mathrm{~min}$, followed by 30 cycles of $94^{\circ} \mathrm{C}$ for $1 \mathrm{~min}, 44^{\circ} \mathrm{C}$ for $1 \mathrm{~min}$, and $72^{\circ} \mathrm{C}$ for $1 \mathrm{~min} 20 \mathrm{~s}$, with a final extension at $72^{\circ} \mathrm{C}$ for $7 \mathrm{~min}$. The PCR products were confirmed using $1 \%$ agarose gel electrophoresis in $0.5 \mathrm{X}$ TBE and visualized by staining with ethidium bromide. The successful amplicons were purified using a Zymoclean Gel DNA Recovery Kit (Zymo Research, Irvine, CA, USA). The purified PCR products were directly sequenced with the same primers used for the PCR using an ABI3730XL sequencer (Applied Biosystems, Foster City, CA, USA), following the manufacturer's instructions.

\section{Data analysis}

Geneious Pro v6 (Kearse et al., 2012) was used to proofread and assemble the contigs. Two analyses were performed for species identification. The obtained sequences were searched within the National Center for Biotechnology Information (NCBI) database using the nucleotide-nucleotide Basic Local Alignment Search Tool (BLASTn). Alignment of 51 cytochrome $b$ sequences was performed using Clustal W v2.1 (Larkin et al., 2007). A neighbor-joining (NJ) tree was constructed using a Kimura 2-parameter model in Mega v7.0 (Kumar et al., 2016) and confidence levels for internal lineages were assessed using 1,000 bootstrap replicates. Twenty-three cytochrome $b$ sequences of cetaceans that had background records of bycatch in South Korea were retrieved from the GenBank database 
for the phylogenetic analyses (AF084055.1, AF084057.1, AF084059.1, AF084060.1, AF084064.1, AF084067.1, AF084077.1, AF084092.1, AF084095.1, AF084103.1, AF304073.1, AY579554.1, DQ378164.1, HQ108420.1, KJ586849.1, KJ586854.1, KJ586853.1, U09679.1, U72039.1, X75583.1, X92536.1, X92540.1, and X92541.1).

\section{RESULTS AND DISCUSSION}

The mitochondrial cytochrome $b$ gene (806-1,140 bp) was successfully amplified in 51 of the 54 collected whale meat samples. The remaining three samples did not amplify because of low quality DNA and were thus excluded from further analyses. The sequences obtained in this study were examined using BLASTn in NCBI (Table 1) and a phylogenetic tree was constructed using the aligned sequences. Results of the phylogenetic tree and BLASTn search demonstrated that the samples of whale meat were mostly comprised of one baleen whale (minke whale) and two toothed whale species (narrow-ridged finless porpoise and common dolphin) (Figure 1). The highest proportion of whale meat was from minke whale (52\%), followed by the narrow-ridged finless porpoise (26\%) and common dolphin $(22 \%)$. These three species also accounted for the highest percentages of officially recorded bycatch in South Korea (Table 2). We found that the number of narrow-ridged finless porpoise individuals as bycatch had increased exponentially from 2001 (17 individuals) to 2012 (2,107 individuals) (Table 2). However, we identified fewer species than Baker et al. (2006), who identified three baleen and 13 toothed-whale species in similar samples from South Korea.

It is concerning that narrow-ridged finless porpoises and common dolphins comprised a significant proportion of whale meat sales in South Korea. These species might be disguised as minke whale meat in the markets because of the supply and demand of these species and because of the difference in the market value of the different meats. In South Korea, whale meat consumers favor minke whale meat over other cetacean species because of its flavor. Han (2012) reported that 400 individuals of minke whale are necessary to meet the annual domestic demand. However, the official, mean annual number of minke whales available from bycatch has been far less, at $\sim 80$ per year, for the last 10 years (Table 2). Conversely, a large number of narrow-ridged finless porpoises, which are not as popular with consumers, are caught as bycatch every year. The imbalance between supply and demand of minke whale meat and narrow-ridged finless porpoise meat has also resulted in a large difference in market value between these two species. The price of minke whale meat is $\sim 60$ times that of narrow-ridged finless porpoise meat in South Korean markets. This difference in market value is presumably a strong incentive for merchants to disguise a species that has a high rate of bycatch, such as narrow-ridged finless porpoise and common dolphin, as the species that has high consumer demand, i.e., minke whale.

Recently, the narrow-ridged finless porpoise population of South Korea has dramatically declined by $\sim 70 \%$ over six years (2004/2005 to 2011) (Park et al., 2015). Bycatch is likely a major factor accelerating the decline in the population size of this species. At the end of 2016, the government of South Korea designated the narrow-ridged finless porpoise of South Korea as an endangered marine species, which thus prohibits any kind of trade of this species. Our results highlighted the possibility that IUU exploitation and trade in narrow-ridged finless porpoise persists among fishermen and merchants because of its potential economic value as disguised minke whale meat. 
Table 1. Molecular species assignment of cetacean meat samples from Korean restaurants and markets, including scores and percentage sequence similarities with GenBank.

\begin{tabular}{|c|c|c|c|c|c|c|}
\hline Sample ID & Collection Year & Locality & Species & Score & & Max Ident (\%) \\
\hline WM1 & 2012 & Ulsan & common dolphin & & 2054 & 99 \\
\hline WM2 & 2012 & Ulsan & narrow-ridged finless porpoise & & 2102 & 100 \\
\hline WM3 & 2012 & Ulsan & common dolphin & & 2061 & 99 \\
\hline WM4 & 2012 & Ulsan & common dolphin & & 2058 & 99 \\
\hline WM5 & 2012 & Ulsan & minke whale & & 1592 & 98 \\
\hline WM6 & 2012 & Ulsan & common dolphin & & 2039 & 99 \\
\hline WM7 & 2012 & Ulsan & narrow-ridged finless porpoise & & 2095 & 99 \\
\hline WM8 & 2012 & Ulsan & common dolphin & & 1872 & 99 \\
\hline WM9 & 2012 & Ulsan & common dolphin & & 2056 & 99 \\
\hline WM10 & 2012 & Pohang & minke whale & & 2025 & 99 \\
\hline WM11 & 2012 & Pohang & minke whale & & 2028 & 99 \\
\hline WM12 & 2012 & Pohang & minke whale & & 2028 & 99 \\
\hline WM13 & 2012 & Pohang & minke whale & & 2023 & 99 \\
\hline WM14 & 2012 & Pohang & narrow-ridged finless porpoise & & 2095 & 100 \\
\hline WM15 & 2012 & Pohang & narrow-ridged finless porpoise & & 2102 & 100 \\
\hline WM16 & 2012 & Pohang & common dolphin & & 2061 & 99 \\
\hline WM17 & 2012 & Pohang & narrow-ridged finless porpoise & & 2084 & 100 \\
\hline WM18 & 2012 & Pohang & narrow-ridged finless porpoise & & 2095 & 100 \\
\hline WM19 & 2012 & Pohang & narrow-ridged finless porpoise & & 1435 & 99 \\
\hline WM20 & 2012 & Pohang & narrow-ridged finless porpoise & & 2095 & 100 \\
\hline WM21 & 2012 & Busan & common dolphin & & 2039 & 99 \\
\hline WM22 & 2012 & Busan & minke whale & & 2034 & 99 \\
\hline WM23 & 2012 & Busan & minke whale & & 2025 & 99 \\
\hline WM24 & 2012 & Busan & minke whale & & 1999 & 99 \\
\hline *WM 25 & 2012 & Busan & Not identified & & & \\
\hline WM26 & 2012 & Busan & minke whale & & 2001 & 99 \\
\hline *WM27 & 2015 & Seoul & Not identified & & & \\
\hline WM28 & 2015 & Seoul & narrow-ridged finless porpoise & & 2058 & 100 \\
\hline WM29 & 2015 & Seoul & minke whale & & 1591 & 98 \\
\hline WM30 & 2015 & Ulsan & minke whale & & 1591 & 99 \\
\hline WM31 & 2015 & Ulsan & narrow-ridged finless porpoise & & 1613 & 99 \\
\hline WM32 & 2015 & Ulsan & narrow-ridged finless porpoise & & 1602 & 98 \\
\hline WM33 & 2015 & Ulsan & minke whale & & 1618 & 99 \\
\hline WM34 & 2015 & Ulsan & minke whale & & 1574 & 99 \\
\hline WM35 & 2015 & Ulsan & common dolphin & & 1664 & 99 \\
\hline WM36 & 2015 & Ulsan & minke whale & & 1574 & 99 \\
\hline WM37 & 2015 & Ulsan & minke whale & & 1168 & 100 \\
\hline WM38 & 2015 & Ulsan & minke whale & & 1151 & 99 \\
\hline WM39 & 2015 & Ulsan & minke whale & & 1672 & 99 \\
\hline WM40 & 2015 & Pohang & minke whale & & 1692 & 98 \\
\hline WM41 & 2015 & Pohang & common dolphin & & 2037 & 99 \\
\hline WM42 & 2015 & Pohang & minke whale & & 1445 & 99 \\
\hline WM43 & 2015 & Pohang & minke whale & & 1711 & 98 \\
\hline WM44 & 2015 & Busan & minke whale & & 1168 & 100 \\
\hline WM45 & 2015 & Busan & minke whale & & 1613 & 99 \\
\hline WM46 & 2015 & Busan & narrow-ridged finless porpoise & & 1493 & 98 \\
\hline WM47 & 2015 & Busan & minke whale & & 1836 & 98 \\
\hline WM48 & 2015 & Busan & minke whale & & 1753 & 98 \\
\hline WM49 & 2015 & Busan & narrow-ridged finless porpoise & & 2074 & 100 \\
\hline *WM50 & 2015 & Busan & Not identified & - & & \\
\hline WM51 & 2015 & Busan & minke whale & & 1681 & 99 \\
\hline WM52 & 2015 & Busan & minke whale & & 1807 & 99 \\
\hline WM53 & 2015 & Pohang & narrow-ridged finless porpoise & & 1650 & 100 \\
\hline WM54 & 2015 & Pohang & minke whale & & 1720 & 99 \\
\hline
\end{tabular}

* Unsuccessfully sequenced 


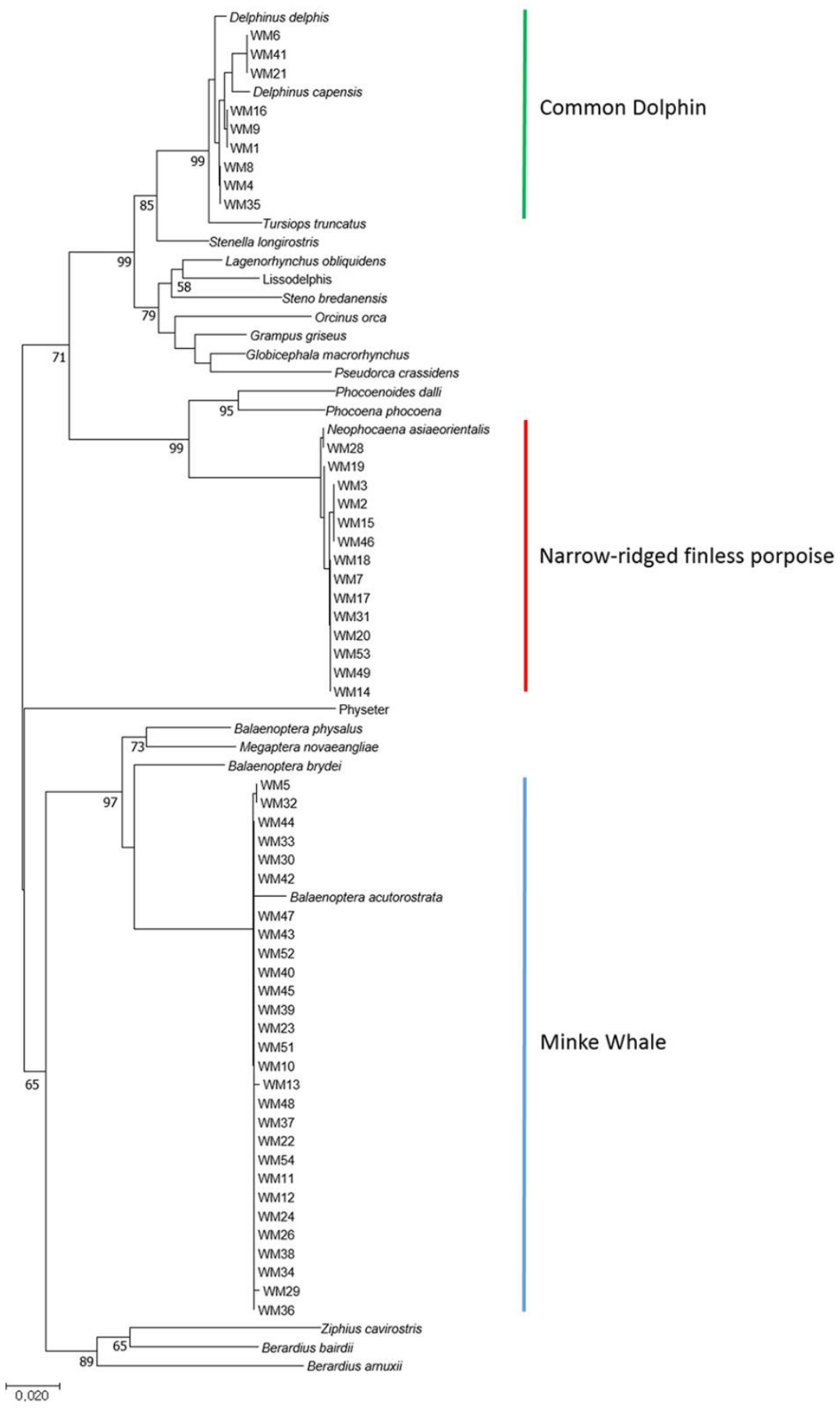

Figure 1. Phylogenetic identification of 'whale meat' products based on the mtDNA cytochrome $b$ gene. Fiftyone sequences were successfully obtained, which consisted of three species: minke whale $(52 \%)$, finless porpoise $(26 \%)$, and common dolphin $(22 \%)$. 
Table 2. Summary of officially reported bycatch of baleen whales and small cetaceans from South Korea.

\begin{tabular}{|c|c|c|c|c|c|c|c|c|c|c|c|c|c|}
\hline & $2000^{\mathrm{a}}$ & $2001^{\mathrm{a}}$ & $2002^{\mathrm{a}}$ & $2003^{\mathrm{a}}$ & $2004^{\mathrm{a}}$ & $2005^{\mathrm{a}}$ & $2006^{a}$ & $2007^{\mathrm{a}}$ & $2008^{a}$ & $2009^{a}$ & $2010^{a}$ & $2011^{\mathrm{b}}$ & $2012^{\mathrm{b}}$ \\
\hline Fin whale & & & 1 & & 1 & 1 & 1 & & & & & & \\
\hline Humpback whale & & & & 1 & 1 & 1 & & & & & 1 & 1 & \\
\hline minke whale & 77 & 160 & 83 & 86 & 61 & 106 & 81 & 80 & 81 & 54 & 70 & 74 & 73 \\
\hline Bryde whale & & & & & & & & & & & 1 & 1 & \\
\hline beaked whale & 1 & 4 & 1 & 3 & & 1 & & & 1 & & 1 & & \\
\hline Baird's beaked whale & & 1 & & 1 & & & & & & & & & \\
\hline Cuvier's & & & & & & & & & & & 1 & & \\
\hline Risso's & 20 & 25 & 2 & 2 & 4 & 3 & & 1 & 2 & & & 1 & \\
\hline comm & 29 & 65 & 73 & 113 & 89 & 195 & 345 & 369 & 244 & 252 & 197 & 256 & 325 \\
\hline ded dolphin & 4 & 43 & 54 & 19 & 20 & 47 & 29 & 60 & 21 & 24 & 17 & 21 & 28 \\
\hline Killer v & 1 & & 3 & & 1 & & & & 3 & 2 & & & \\
\hline False & 1 & & & & & & 1 & & 1 & & 1 & & \\
\hline Bottlenose dolphin & 12 & 3 & 4 & 1 & 4 & 15 & & 18 & 4 & 3 & 4 & & 3 \\
\hline Indo pacific bottlen & & & & & & & & & 2 & 9 & 6 & 1 & \\
\hline Rough-tc & 1 & 1 & & & & & & & & & & & \\
\hline Dall's & 2 & 2 & 1 & & 1 & 1 & & & 1 & & & & \\
\hline Harb & & 88 & 34 & 105 & 22 & 102 & 55 & 5 & 15 & 36 & 45 & 26 & 10 \\
\hline Finless porpoise & & 17 & 15 & 82 & 13 & 32 & 30 & 57 & 347 & 159 & 232 & 665 & 2107 \\
\hline Spinn & & & & & & & & & & & & 1 & 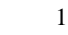 \\
\hline Unidentified dolphin & 27 & & 2 & 1 & 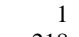 & 2 & & & & & & & \\
\hline
\end{tabular}

${ }^{\text {a }}$ data obtained from the National Progress Reports to the International Whaling Commission by the Republic of Korea.

${ }^{\mathrm{b}}$ data obtained from Kim et al. (2013)

Whale meat, mainly minke whale, is a local food in South Korea, and the demand for this meat is expected to continue. Our study showed that this culture also affects the future of other whale species in South Korea. Effective and systematic monitoring is therefore required to identify species and the number of individuals that appear in the markets. Generally, it is impossible to identify the species of bushmeat samples based on their external characteristics. A molecular capture-recapture approach is a more useful method to detect illegal poaching of wildlife (Gupta et al., 2006; An et al., 2007; Dalton and Kotze, 2011). To reduce IUU exploitation of narrow-ridged finless porpoise, we propose the establishment of a systematic genetic monitoring program for whale meat, including the genetic analysis of market products.

\section{ACKNOWLEDGMENTS}

Funding: This work was supported by the National Research Foundation of Korea funded by the Korean Government [grant number NRF-2014R1A1A2059249], the Korean Federation for Environmental Movement, and the Research Institute for Veterinary Science, Seoul National University.

\section{REFERENCES}

An J, Lee MY, Min MS, Lee MH, et al. (2007). A molecular genetic approach for species identification of mammals and sex determination of birds in a forensic case of poaching from South Korea. Forensic Sci. Int. 167: 59-61.

Baker CS, Lukoschek V, Lavery S, Dalebout ML, et al. (2006). Incomplete reporting of whale, dolphin and porpoise 'bycatch' revealed by molecular monitoring of Korean markets. Anim. Conserv. 9: 474-482.

Baker CS, Steel D, Choi Y, Lee H, et al. (2010). Genetic evidence of illegal trade in protected whales links Japan with the US and South Korea. Biol. Lett. 6: 647-650.

Costello MJ and Baker CS (2011). Who eats sea meat? Expanding human consumption of marine mammals. Biol. Conserv. 144: 2745-2746. 
Dalton DL and Kotze A (2011). DNA barcoding as a tool for species identification in three forensic wildlife cases in South Africa. Forensic Sci. Int. 207: e51-54.

Gupta SK, Thangaraj K and Singh L (2006). A simple and inexpensive molecular method for sexing and identification of the forensic samples of elephant origin. J. Forensic Sci. 51: 805-807.

Han J (2012). Disappearing Whales: Korea's Inconvenient Truth. Greenpeace, Korea.

Hashimoto M, Shirakihara K and Shirakihara M (2015). Effects of bycatch on the population viability of the narrowridged finless porpoises in Ariake Sound and Tachibana Bay, Japan. Endanger. Species Res. 27: 87-94.

Irwin DM, Kocher TD and Wilson AC (1991). Evolution of the cytochromeb gene of mammals. J. Mol. Evol. 32: 128144.

Jain S, Brahmbhatt MN, Rank DN, Joshi CG, et al. (2007). Use of cytochrome $b$ gene variability in detecting meat species by multiplex PCR assay. Indian J. Anim. Sci. 77: 880-881.

Kearse M, Moir R, Wilson A, Stones-Havas S, et al. (2012). Geneious Basic: An integrated and extendable desktop software platform for the organization and analysis of sequence data. Bioinformatics. 28: 1647-1649.

Kim DN, Sohn H, An Y-R, Park KJ, et al. (2013). Status of the cetacean bycatch near Korean waters. Korean J. Fish. Aquat. Sci. 46: 892-900.

Kumar S, Stecher G and Tamura K (2016). MEGA7: Molecular evolutionary genetics analysis version 7.0 for bigger datasets. Mol. Biol. Evol. 33: 1870-1874.

Larkin MA, Blackshields G, Brown NP, Chenna R, et al. (2007). Clustal W and Clustal X version 2.0. Bioinformatics. 23: 2947-2948.

Lewison RL, Crowder LB, Read AJ and Freeman SA (2004). Understanding impacts of fisheries bycatch on marine megafauna. Trends Ecol. Evol. 19: 598-604.

Morell V (2017). World's most endangered marine mammal down to 30. Science. 355: 558-559.

Park KJ, Sohn H, An YR, Kim HW, et al. (2015). A new abundance estimate for the finless porpoise Neophocaena asiaeorientalis on the west coast of Korea: An indication of population decline. Fish. Aquat. Sci. 18: 411-416.

Peltier H, Authier M, Deaville R, Dabin W, et al. (2016). Small cetacean bycatch as estimated from stranding schemes: The common dolphin case in the northeast Atlantic. Environ. Sci. Policy. 63: 7-18

Perrin WF, Donovan GP and Barlow J (1994). Gillnets and cetaceans: incorporating the proceedings of the symposium and workshop on the mortality of cetaceans in passive fishing nets and traps. Cambridge: International Whaling Commission. Conference proceedings Wageningen University \& Research - Library.

Read AJ, Drinker P and Northridge S (2006). Bycatch of Marine Mammals in U.S. and Global Fisheries. Conserv. Biol. 20: $163-169$.

Reeves RR, Wang JY and Leatherwood S (1997). The finless porpoise, Neophocaena phocaenoides (G Cuvier, 1829): a summary of current knowledge and recommendations for conservation action. Asian Mar. Biol. 14: 111-143.

Sanches A, Tokumoto PM, Peres WA, Nunes FL, et al. (2012). Illegal hunting cases detected with molecular forensics in Brazil. Investig. Genet. 3: 17.

Tatar B (2014). The safety of bycatch: South Korean responses to the moratorium on commercial whaling. J. Mar. Isl. Cult. 3: 89-97. 